\title{
MR Characteristics of Malignant Spinal Cord Astrocytomas in Children
}

\author{
Abhaya V. Kulkarni, Derek C. Armstrong and James M. Drake
}

\begin{abstract}
Objective: Malignant spinal cord astrocytomas are rare tumors and their specific MR characteristics have not been previously described. We present a detailed MR analysis of four children with malignant astrocytoma. Methods: A review of the clinical database at the Hospital for Sick Children, Toronto revealed four patients with histologically-verified malignant spinal cord astrocytomas (WHO Grade 3 or 4) with pre-operative MR available for retrospective review. Results: There were three boys and one girl with a mean age at presentation of four years (range 7 months - 12 years). Mean duration of symptoms prior to presentation was six weeks (range 3 days -5 months). Pre-operative MR analysis revealed that all tumors were located in the cervical or cervico-thoracic regions and expanded the cord over an average of 6.5 vertebral levels. The signal was usually hypointense on T1-weighted and hyperintense or mixed intensity on T2-weighted images. In the three cases where gadolinium was given, all demonstrated enhancement (one rim enhancement with a discrete border and two with inhomogeneous central enhancement). One tumor appeared to be exophytic, one had a significant cystic component, and none showed evidence of hemorrhage. Pre-operative leptomeningeal spread of tumor was documented in two of four cases and involved intracranial spread in both cases. Conclusions: There did not appear to be any specific MR characteristics to help differentiate a malignant astrocytoma from a low-grade tumor, except for the high rate of leptomeningeal spread at presentation. It is recommended that full neuraxis MR imaging be performed pre-operatively in children in whom a rapidly progressive clinical course suggests a malignant lesion. This will likely have a high positive yield and provide valuable information prior to surgical intervention.
\end{abstract}

RÉSUMÉ: Caractéristiques à l'IRM de l'astrocytome malin de la moelle épinière chez les enfants. Objectif: Les astrocytomes malins de la moelle épinière sont des tumeurs rares et leurs caractéristiques spécifiques à l'imagerie par résonance magnétique (IRM) n'ont jamais été décrites. Nous présentons une analyse détaillée des caractéristiques à l'IRM d'un astrocytome malin chez 4 enfants. Méthodes: Une revue de la base de données cliniques de l'Hôpital pour enfants malades de Toronto a révélé l'existence de 4 patients présentant un astrocytome malin de la moelle épinière vérifié par histologie (OMS grade 3 ou 4) qui avaient des données IRM préopératoires disponibles pour une revue rétrospective des cas. Résultats: Il s'agissait de 3 garçons et de 1 fille dont l'âge moyen au moment de la consultation était de 4 ans (de 7 mois à 12 ans). La durée moyenne des symptômes avant la consultation était de 6 semaines (de 3 jours à 5 mois). L'IMR préopératoire a révélé que toutes les tumeurs étaient localisées dans la région cervicale ou cervico-thoracique et s'étendaient en moyenne sur une longueur de 6.5 vertèbres. Le signal était habituellement hypointense sur les images pondérées en T1 et hyperintense ou d'intensité mixe sur celles pondérées en T2. Chez les 3 cas où on a administré du gadolinium, on a observé un rehaussement ( 1 avec rehaussement du périmètre avec une bordure discrète et 2 avec un rehaussement central non homogène) Une tumeur semblait exophytique, une avait une composante kystique importante et aucune ne manifestait de signe d'hémorragie. Un envahissement des leptoméninges par la tumeur a été documenté chez 2 des 4 cas et comportait un envahissement intracrânien dans les deux cas. Conclusions: Il ne semblait pas y avoir de caractéristiques spécifiques à l'IRM pour aider à différencier l'astrocytome malin d'une tumeur de faible malignité à part le taux élevé d'envahissement des leptoméninges au moment de la consultation. Il est recommandé de procéder à l'IRM de l'encéphale et de la moelle épinière avant la chirurgie chez les enfants qui présentent une évolution clinique rapide suggérant une lésion maligne. Cette investigation aura vraisemblablement un taux élevé de résultats positifs et fournira de l'information importante avant la chirurgie.

Can. J. Neurol. Sci. 1999; 26: 290-293

Magnetic resonance imaging (MR) has become the standard for the diagnosis and follow-up of spinal cord tumors. While previous reports have documented the MR features of intramedullary spinal cord tumors, ${ }^{1-5}$ no previous work has provided a detailed analysis of the MR characteristics of malignant, high-grade spinal astrocytoma, a particularly rare sub-group of tumor. It would be valuable to know if there are any specific MR features that might suggest the diagnosis of a malignant tumor prior to surgery. This report presents a detailed documentation of the MR characteristics of four histologically verified high-grade spinal cord astrocytomas treated at the Hospital for Sick Children, Toronto in an attempt to define such characteristics.

\section{Methods:}

A review of the clinical database from the Division of Neurosurgery at the Hospital for Sick Children, Toronto revealed four patients with the diagnosis of malignant, high-grade spinal cord astrocytoma with pre-operative MR imaging available for analysis. High-grade astrocytoma was defined as Grade 3 or

From the Divisions of Neurosurgery and Neuroradiology, Hospital for Sick Children, University of Toronto, Toronto, Canada.

RECEIVED MARCH 23, 1999. ACCEPTED IN FINAL FORM AUGUST 3, 1999

Reprint requests to: James M. Drake, Division of Neurosurgery Hospital for Sick Children, 555 University Avenue, Toronto, Ontario, Canada M5G 1X8 
Table: MR Characteristics of Malignant Spinal Cord Astrocytomas

\begin{tabular}{|c|c|c|c|c|c|c|c|c|c|c|c|c|c|}
\hline \multicolumn{2}{|c|}{$\begin{array}{l}\text { CaseAge at } \\
\text { Diagnosis }\end{array}$} & $\begin{array}{l}\text { Symptom } \\
\text { Duration }\end{array}$ & $\begin{array}{c}\mathrm{T} 1 \\
\text { signal }\end{array}$ & $\begin{array}{c}\mathrm{T} 2 \\
\text { signal }\end{array}$ & $\begin{array}{c}\text { Cord } \\
\text { Expansion }\end{array}$ & $\begin{array}{c}\text { Cord } \\
\text { Enhancement }\end{array}$ & $\begin{array}{c}\text { Cord } \\
\text { Edema }\end{array}$ & Cystic & Exophytic & $\begin{array}{c}\text { Axial } \\
\text { Location }\end{array}$ & $\begin{array}{c}\text { Leptomeningeal } \\
\text { Metastasis }\end{array}$ & Surgery & Outcome \\
\hline 1 & $7 \mathrm{mths}$ & $5 \mathrm{mths}$ & hypo & hypo & $\mathrm{C} 1-\mathrm{C} 7$ & $\mathrm{n} / \mathrm{a}$ & $\mathrm{C} 1-\mathrm{C} 7$ & no & no & central & no & GTR & alive at $66 \mathrm{mths}$ \\
\hline 2 & 9 mths & 3 days & hypo & mixed & C3-T5 & $\mathrm{T} 1-\mathrm{T} 5$ & CMJ-T5 & no & no & central & no & GTR & alive at $78 \mathrm{mths}$ \\
\hline 3 & 3 years & 5 days & hypo & mixed & $\mathrm{C} 2-\mathrm{T} 2$ & CMJ-T2 & CMJ-T5 & no & no & central & yes & STR & dead at $4 \mathrm{mths}$ \\
\hline 4 & 12 years & 7 days & $\mathrm{n} / \mathrm{a}$ & hyper & $\mathrm{T} 1-\mathrm{T} 4$ & $\begin{array}{l}\text { T1-T4, } \\
\text { inhomo }\end{array}$ & C7-T5 & yes & yes & $\begin{array}{l}\text { right } \\
\text { dorsal }\end{array}$ & yes & biopsy & alive at $10 \mathrm{mths}$ \\
\hline
\end{tabular}

$\mathrm{CMJ}=$ cervicomedullary junction; hypo = hypointense; hyper = hyperintense; inhomo = inhomogeneous; mixed = hypo- and hyper-intense; incr = increased; mths = months; GTR = gross total resection; STR = subtotal resection

Grade 4 astrocytoma by World Health Organization (WHO) criteria. $^{6}$

The clinical and operative records were reviewed retrospectively for each patient. As well, all available pre-operative imaging was reviewed by a neuroradiologist. Specific features of the MR findings, including signal intensity, extent of cord expansion, cord edema, gadolinium enhancement pattern, and the presence of cysts and tumor spread, were recorded in detail.

\section{RESULTS:}

There were four patients with high-grade spinal cord astrocytomas who had pre-operative MR imaging available for review. These children presented between 1989 and 1997 at a mean age of four years (range 7 months - 12 years old) (Table). There were three boys and one girl. The mean duration of symptoms prior to presentation was six weeks (range three days
- five months). Presenting signs and symptoms included arm/leg weakness (all cases), acute apnea and quadriparesis (one case), neck pain (one case), and hydrocephalus (one case).

All patients went on to surgical resection with gross-total resection performed in two patients, sub-total resection in one patient, and biopsy only in one patient. The intra-operative gross description was most commonly that of a purply-grey, gelatinous tumor. Histological examination revealed a diagnosis of anaplastic astrocytoma (WHO Grade 3) in three cases and glioblastoma (WHO Grade 4) in one case.

Magnetic resonance imaging studies of the four cases revealed that all tumors were located in the cervical or cervicothoracic regions and expanded the cord over an average of 6.5 vertebral levels (Table). Signal intensity, relative to spinal cord tissue, was hypointense on T1-weighted images and varied on T2-weighted images. In the three cases in which gadolinium
$\mathbf{A}$

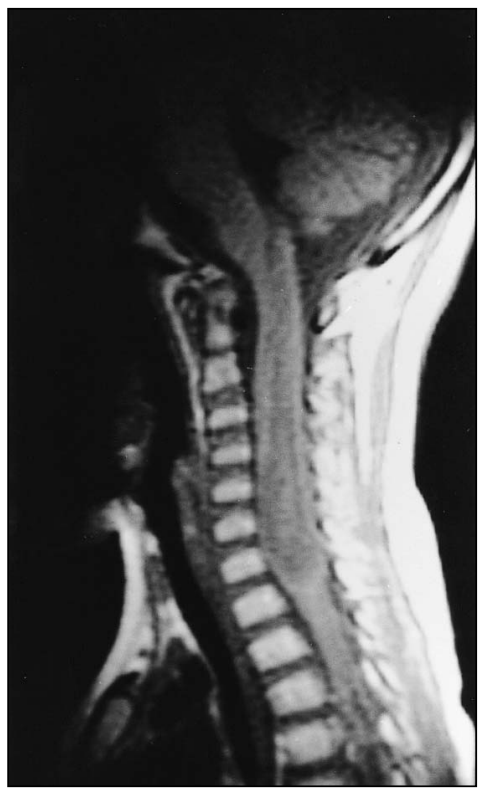

B

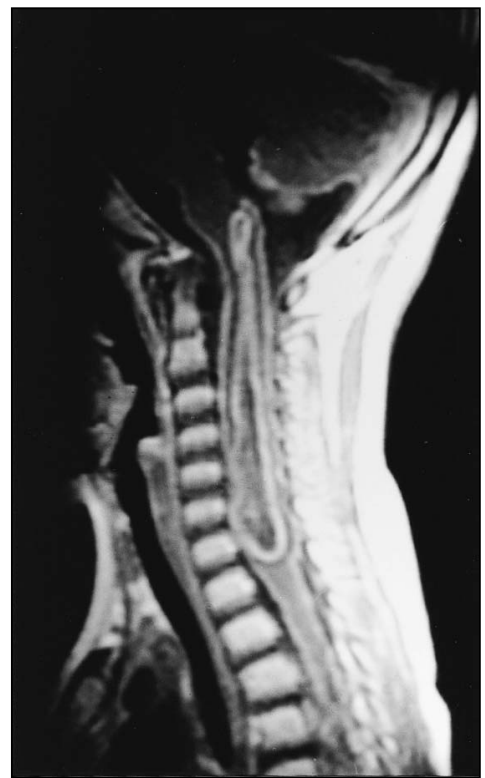

Figure 1: Sagittal T1-weighted MR without gadolinium (A) and with gadolinium (B) from Case 3. Note the rim enhancement pattern of the tumor itself and the diffuse leptomeningeal enhancement that coats the surface of the spinal cord, brainstem and cerebellum. 

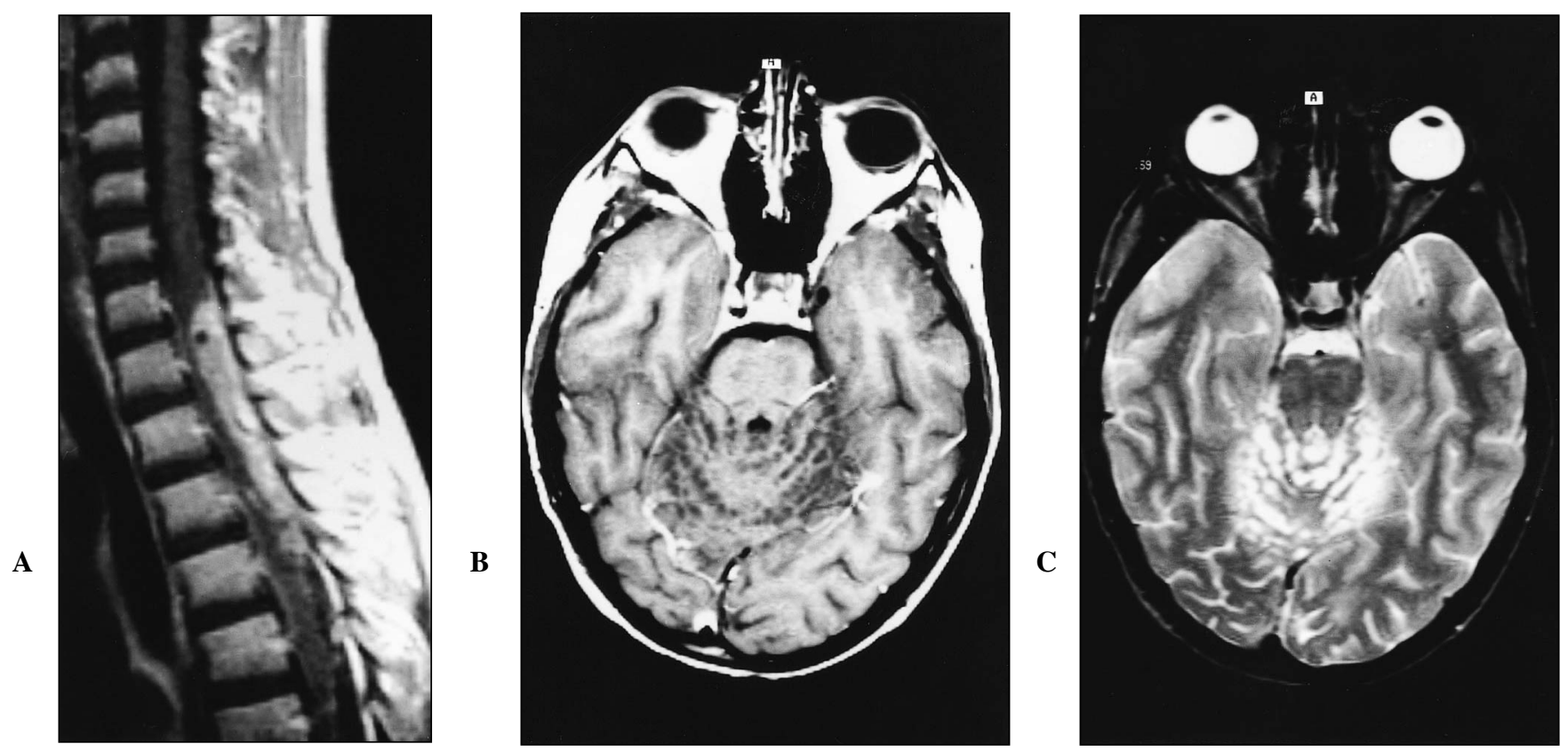

Figure 2: Sagittal T1-weighted MR with gadolinium (A) demonstrating the enhancing spinal cord tumor from Case 4. Axial gadolinium-enhanced T1-weighted $(\boldsymbol{B})$ and T2-weighted $(\boldsymbol{C})$ MR of the brain in the same patient demonstrates coating of the cerebellar folia with leptomeningeal metastases. The signal characteristics of these cerebellar metastases are quite unusual, particularly the lack of gadolinium enhancement. Open biopsy demonstrated a grossly normal appearance to the cerebellar surface, but pathological examination confirmed the presence of metastases.

was given, all displayed enhancement, either rim enhancement (one case) or central inhomogeneous enhancement (two cases) (Figures 1 and 2). There did not appear to be evidence of intratumoral hemorrhage. For the cases in which T2-weighted hypointensity was seen, this was not felt to be dark enough to represent hemorrhage. As well, in two cases, pre-operative imaging revealed the presence of leptomeningeal tumor spread, both involving the intracranial region (Figures 1 and 2).

\section{DISCUSSION}

High-grade astrocytoma of the spinal cord is a very uncommon tumor for which a detailed description of the MR findings has not previously been documented. Other series have described the MR appearance of low-grade spinal cord astrocytomas and other intramedullary spinal cord tumors. ${ }^{1-5,7}$ This brief report describes in detail the MR findings of four histologically-verified high grade spinal cord astrocytomas (WHO Grade 3 or 4).

The clinical presentation of these children was strikingly rapid, with a mean duration of symptoms of only six weeks prior to presentation. This is consistent with previous clinical studies of malignant spinal cord astrocytomas ${ }^{8}$ and contrasts sharply with the classically indolent course of low-grade spinal cord tumors, which present over several months or even years. ${ }^{9-11}$

Analysis of the MR findings did not reveal any specific features of the local tumor that would help differentiate it from the more common low-grade lesions. The MR signal intensities and enhancement pattern did not appear significantly different from descriptions of low-grade astrocytomas. ${ }^{1-5,7}$ The longitudinal extent of the tumor over 6.5 vertebral segments was only slightly greater than the 4 vertebral segments that has been documented for low-grade tumors. ${ }^{7}$ However, the one feature that was very striking was the high rate of leptomeningeal tumor spread at presentation (two of four cases). The documentation of this on pre-operative imaging was certainly in keeping with a malignant lesion. Leptomeningeal spread during the clinical course of a malignant spinal cord astrocytoma is a well documented occurrence. ${ }^{8,12-16}$ Cohen et al. reported in their series of malignant spinal cord astrocytomas a rate of 58\%. ${ }^{8}$ There have also been reports in the literature of low-grade spinal cord astrocytomas developing leptomeningeal spread. ${ }^{14,15,17-21}$ However, in many of these cases, although the tumor was considered low-grade on the initial surgical specimen, further evaluation, usually at post-mortem, confirmed the presence of malignant astrocytoma in, at least, a portion of the tumor. ${ }^{17,18,21}$ Hardison et al. reported four patients with disseminated spinal cord astrocytomas: two diagnosed at presentation and two at first relapse. Half of these cases were apparently low-grade astrocytomas, yet their survival was identical to the two patients with malignant astrocytomas (3 months and 11 months). ${ }^{14}$ It is probable that most cases of leptomeningeal spread of so-called low-grade spinal cord astrocytomas more likely represent a sampling error of a malignant lesion.

Although the high rate of leptomeningeal metastases at diagnosis may partially be explained by our small sample size or the increased sensitivity of MR over computerized tomogram (CT) myelography, similar results were observed by the recent multi-center Children's Cancer Group study. ${ }^{22}$ They documented the presence of leptomeningeal metastases in six of 13 patients at the time of diagnosis of a spinal high-grade 
astrocytoma. This adds some credibility to this being a true phenomenon rather than a spurious finding. By crudely combining the results of our series with those of the Children's Cancer Group, the incidence of leptomeningeal metastases at presentation is $47 \%(8 / 17)$ with an approximate $95 \%$ confidence interval of $23 \%$ to $71 \%$.

Given this high rate of early cerebrospinal fluid (CSF) spread, it is advisable that children presenting with an intramedullary spinal cord tumor, in the face of a rapidly progressive clinical picture suggestive of a malignant lesion, should have full neuraxis MR performed. In the appropriate setting, this imaging would appear to have a relatively high positive yield for CSF dissemination. The presence of documented intracranial seeding would perhaps alter the surgical goals, opting for a less aggressive, less morbid resection expecting a diagnosis of malignant spinal cord tumor. This would be further verified by intra-operative quick section pathological examination. Post-operative adjuvant therapy would also be altered by the early documentation of CSF spread, particularly with the use of craniospinal irradiation. The Children's Cancer Group study recommended chemotherapy and craniospinal irradiation for this group of patients, although the latter was not specifically studied in their recent report. ${ }^{22}$

\section{CONCLuSIONS}

There is a high rate of leptomeningeal metastases from highgrade spinal cord astrocytomas at presentation in children. The other MR characteristics of these tumors are non-specific in differentiating them from low-grade lesions. It is recommended that in those children in whom a rapidly progressive clinical course suggests a malignant spinal cord tumor, full neuraxis MR be performed in order to rule out CSF dissemination.

\section{ACKNOWLEDGEMENTS}

Dr. Kulkarni is supported by the Duncan L. Gordon Fellowship from the Hospital for Sick Children Foundation, Toronto.

\section{REFERENCES}

1. Li MH, Holtas S. MR imaging of spinal intramedullary tumors. Acta Radiologica 1991; 32:505-513.

2. Parizel PM, Baleriaux D, Rodesch G, et al. Gd-DTPA-Enhanced MR imaging of spinal tumors. Am J Neuroradiol 1989; 152:10871096

3. Rossitch E, Zeidman SM, Burger PC, et al. Clinical and pathological analysis of spinal cord astrocytomas in children. Neurosurgery
1990; 27:193-196.

4. Rothwell CI, Jaspan T, Worthington BS, Holland IM. Gadoliniumenhanced magnetic resonance imaging of spinal tumours. $\mathrm{Br} \mathrm{J}$ Radiol 1989; 62:1067-1074.

5. Takemoto K, Matsumura Y, Hashimoto $\mathrm{H}$, et al. MR imaging of intraspinal tumors - capability in histological differentiation and compartmentalization of extramedullary tumors. Neuroradiology 1988; 30:303-309.

6. Kleihues P, Burger PC, Scheithauer BW. Histological Classification of Tumours of the Central Nervous System. Springer-Verlag, 1993.

7. Patel U, Pinto RS, Miller DC, et al. MR of spinal cord ganglioglioma. Am J Neuroradiol 1998; 19:879-887.

8. Cohen AR, Wisoff JH, Allen JC, Epstein F. Malignant astrocytomas of the spinal cord. J Neurosurg 1989; 70:50-54.

9. Minehan KJ, Shaw EG, Scheithauer BW, Davis DL, Onofrio BM. Spinal cord astrocytoma: pathological and treatment considerations. J Neurosurg 1995; 83:590-595.

10. Przybylski GJ, Albright AL, Martinez AJ. Spinal cord astrocytomas: long-term results comparing treatments in children. Child's Nerv Syst $1997 ; 13: 375-382$.

11. Reimer R, Onofrio BM. Astrocytomas of the spinal cord in children and adolescents. J Neurosurg 1985; 63:669-675.

12. Andrews AA, Enriques L, Renaudin J, Tomiyasu U. Spinal intramedullary glioblastoma with intracranial seeding. Report of a case. Arch Neurol 1978; 35:244-245.

13. Cooper PR, Epstein F. Radical resection of intramedullary spinal cord tumors in adults. Recent experience in 29 patients. J Neurosurg 1985; 63:492-499.

14. Hardison HH, Packer RJ, Rorke LB, et al. Outcome of children with primary intramedullary spinal cord tumors. Child's Nerv Syst 1987; 3:89-92.

15. Hely M, Fryer J, Selby G. Intramedullary spinal cord glioma with intracranial seeding. J Neurol Neurosurg Psychiatr 1985; 48:302-309.

16. Johnson DL, Schwarz S. Intracranial metastases from malignant spinal-cord astrocytoma. Case report. J Neurosurg 1987; 66:621625.

17. Claus D, Sieber E, Engelhardt A, et al. Ascending central nervous spreading of a spinal astrocytoma. J Neuro-Oncol 1995; 25:245250.

18. Eade OE, Urich $\mathrm{H}$. Metastasising gliomas in young subjects. J Pathol 1971; 103:245-256.

19. Gajjar A, Bhargava R, Jenkins JJ, et al. Low-grade astrocytoma with neuraxis dissemination at diagnosis. J Neurosurg 1995; 83:6771.

20. Kopelson G, Linggood RM. Intramedullary spinal cord astrocytoma versus glioblastoma. The prognostic importance of histologic grade. Cancer 1982; 50:732-735.

21. Tijssen CC, Sluzewski M. Spinal astrocytoma with intracranial metastases. J Neuro-Oncol 1994; 18:49-52.

22. Allen JC, Aviner S, Yates AJ, et al. Treatment of high-grade spinal cord astrocytoma of childhood with "8-in-1" chemotherapy and radiotherapy: a pilot study of CCG-945. J Neurosurg 1998; $88: 215-220$. 